\title{
The role of Cucurbita pepo in the management of patients affected by lower urinary tract symptoms due to benign prostatic hyperplasia: A narrative review
}

\author{
Rocco Damiano ${ }^{1}$, Tommaso Cai ${ }^{2}$, Paolo Fornara ${ }^{3}$, Corrado Antonio Franzese ${ }^{4}$, \\ Rosario Leonardi ${ }^{5}$, Vincenzo Mirone ${ }^{6}$ \\ ${ }^{1}$ Department of Urology, University of Catanzaro, Catanzaro, Italy; \\ ${ }^{2}$ Department of Urology, Santa Chiara Regional Hospital, Trento, Italy; \\ ${ }^{3}$ Department of Urology, Martin-Luther-University, Halle Saale, Germany; \\ ${ }^{4}$ Urology, ASL NA3 SUD, Naples, Italy; \\ ${ }^{5}$ Urology, GECAS Institute, Catania, Italy; \\ ${ }^{6}$ Department of Urology, University of Naples, Federico II, Naples, Italy.
}

\begin{abstract}
Summary Objective: Phytotherapeutic compounds are largely used in the treatment of lower urinary tract symptoms (LUTS) related to benign prostatic hyperplasia (BPH) due to low side-effect profiles and costs, high level of acceptance by patients and a low rate of dropout. Here, we aimed to analyze all available evidence on the role of Cucurbita pepo in the treatment of LUTS-BPH. Material and methods: In May 2016 a systematic search was carried out thorough National Library of Medicine Pubmed, Scopus database and the ISI Web of Knowledge official website in order to identify all published studies on Cucurbita pepo and BPH. The following search strings were used: "Cucurbita pepo" OR "pumpkin seed" AND

"prostate"; "Cucurbita pepo" AND "antiandrogen" OR "antiproliferative" OR "anti-inflammatory" $O R$ "antioxidant activities"; "cucurbita pepo" OR "pumpkin seed" AND "LUTS" AND "symptoms improvement" OR "quality of life". We consider for the present analysis only studies related to LUTS-BPH.

Results: Among all 670 screened, 16 were related to LUTSBPH and finally analyzed. Among all, ten of them were performed in "in vitro setting" showing anti-inflammatory and antiandrogen effect, and a reduction in prostate growth and detrusor activity, while six were clinical studies. In all studies an improvement in International Prostatic Symptoms Score (IPSS) and uroflowmetry parameters has been reported. In 4 studies, an improvement in quality of life has been reported.

Conclusion: On the basis of our narrative review, the use of Cucurbita pepo in the management of patients affected by LUTS-BPH seems to be useful for improving symptoms and quality of life. However, future clinical trials are requested to confirm these promising results.
\end{abstract}

KEY WORDS: BPH; Cucurbita pepo; LUTS; Prostate disease; Pumpkin seed.

Submitted 27 May 2016; Accepted 5 June 2016

Contributions: RD, TC, CAF, RL data collecting; RD, TC analyzing and manuscript writing; VM, CAF, RL and PF supervision.

\section{INTRODUCTION}

Benign prostatic hyperplasia (BPH) affects most men after the age of 50 years and is considered the most common urologic disease among elderly men (1). BPH is a chronic disease with early initiation and slow progression, due to an overgrowth of the epithelial and stromal cells from the transition zone and the periurethral area (2). It is essentially a histological diagnosis, which can be clinically manifested as benign prostatic enlargement (BPE) in almost half of the cases. BPH starts as a simple micro nodular hyperplasia and evolves into a macroscopic nodular enlargement that gradually results in benign prostatic obstruction (BPO). The increase in prostatic size may eventually compress the urethral canal leading to $\mathrm{BPO}$ characterized by progressive development of lower urinary tract symptoms (LUTS) as urinary hesitancy and frequency, dysuria, sexual dysfunction, increased risk of urinary infection and at least urinary retention. Aging, dietary factors, presence of androgens, growth factors, oxidative stress and chronic prostatic inflammation are necessary for the development and progression of $\mathrm{BPH}$, but the pathogenesis is still largely unresolved and there is no consensus as to which is the primary one (3). In the management of $\mathrm{BPH}$, is necessary to reduce cell growth by blockage of testosterone conversion in DHT, and reduce the sustaining of the chronic prostatic inflammation. Patient acceptability of treatment is key to decreasing the human and economic burden of this condition. Maintaining sexual function is a crucial topic nowadays. Alpha blockers, 5-alphareductase inhibitors (i-5AR) and phosphodiesterase 5 inhibitors (i-PDE5), as monotherapy or in combination, have been used in BPH treatment (4). Notwithstanding these drugs have a positive effect on the patient with BPH, side effects (including sexual ones) progressively favor patient withdrawal from therapy and progressively enhance interest in drugs of plant origin with less adverse effects (5). Phytotherapy dates back thousands of years, and currently represent almost $50 \%$ of all medicine pre- 
scribed for BPH in Italy. Nowaday, due to low side-effect profiles and costs, high level of acceptance by patients and low rate of drop-out, the use of phytotherapy is progressively increasing. Here, we focused our attention on Cucurbita pepo. Cucurbita is a well-known traditional herbal medicinal product used from centuries worldwide and its medicinal use was described in many manuscripts and textbooks. The Cucurbita genus comprises many species widespread in Europe, Asia and America. Cucurbita pepo in the form of ethanolic pumpkin seed soft extract has been used for more than thirty years in the European Community, mainly as a remedy for various difficulties associated with an enlarged prostate gland and micturition problems related to overactive bladder $(6,7)$. The active compounds in Cucurbita pepo L. seeds are $\Delta 5-, \Delta 7$ - and $\Delta 8$-sterols: $\Delta 7$-sterols, which are largely predominant in Cucurbita pepo, are considered to be the key active constituents of pumpkin seed in the treatment of benign prostatic hyperplasia. Much smaller amounts of $\Delta 5$ - and $\Delta 8$-sterols are also present in Cucurbita pepo (7-11). High content of carotenoids, polyunsaturated fatty acids and liposoluble vitamins have also a role in its activity (12). Therefore, in the present narrative review, we summarize all evidence available on the role of Cucurbita pepo in the management of patients affected by LUTS due to BPH.

\section{MATERIALS AND METHODS}

\section{Search strategy and evidence acquisition}

We searched electronic databases including PubMed, the Scopus database and the ISI Web of Knowledge for published studies that analyzed the role of Cucurbita pepo in the management of patients affected by LUTS due to BPH up to May 31, 2016. The following Medical Subject Headings terms and free text were used: "Cucurbita pepo" OR "pumpkin seed" AND "prostate"; "Cucurbita pepo" AND "antiandrogen" OR "antiproliferative" OR "anti-inflammatory" OR "antioxidant activities"; "cucurbita pepo" OR "pumpkin seed" AND "LUTS" AND "symptoms improvement" OR "quality of life". There was no restriction on population or publication year. Additionally, we conducted a manual search using the bibliographies of all the identified studies, reviews, and editorials to identify references that we may have missed during our primary search. Finally, the search included original articles, review articles and editorials and these were reviewed in order to select relevant articles. When necessary, we contacted the authors to obtain any relevant information we found to be missing from published papers.

The Figure 1 shows the study selection process diagram.

\section{Selection criteria}

Inclusion criteria: (1) all studies related to LUTS-BPH; (2) all pre-clinical and clinical trials.

Exclusion criteria: (1) the language of the studies was not English or German; (2) if multiple publications for the same data from the same study group occurred, only the most informative and recent article was recruited into final analysis; (3) letters to Editor, review articles, commentaries, clinical guidelines, or case reports and case series.
Figure 1.

Selection process of studies.

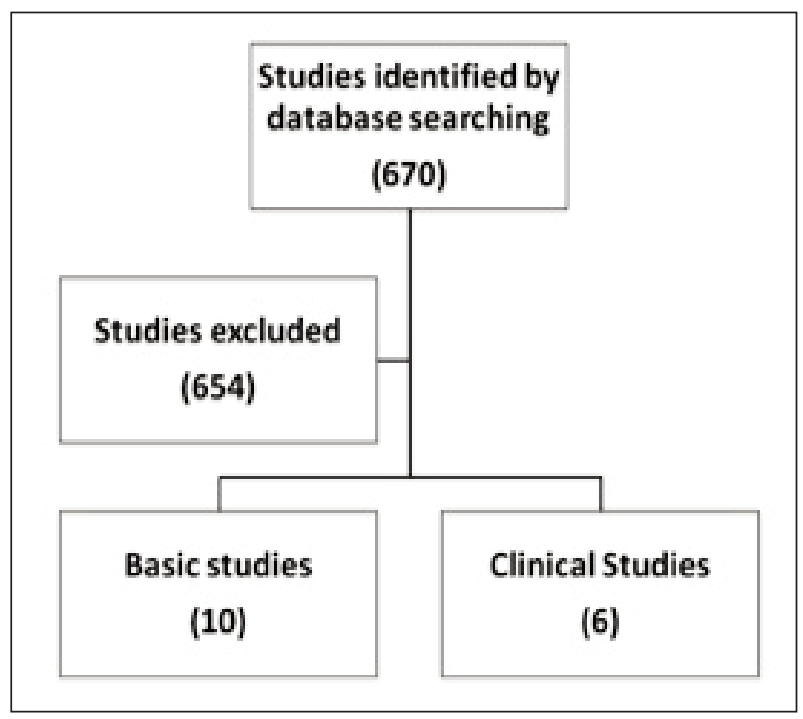

\section{RESULTS}

Six-hundred and seventy studies were selected up to May 31, 2016. After the first-step analysis, 16 studies were included in this narrative review. Ten studies were considered in the pre-clinical setting and 6 in the clinical setting.

\section{Pre-clinical setting}

Antioxidant activity. Four commercially available pumpkin seeds (Cucurbita pepo, Cucurbita moschata, Cucurbita maxima and Cucurbita mixta) extracts were screened for their antioxidant activity and their inhibitory activity against lipid peroxidation (13). The results showed that radical scavenging activity depends on their total phenolic content. In particular, pumpkin seed water extracts inhibited lipid peroxidation at $1.5 \mathrm{mg} / \mathrm{ml}$, while the acetone extracts inhibit $50 \%$ of lipoxygenase activity at the range from 0.16 to $0.80 \mathrm{mg} / \mathrm{ml}$.

Antiandrogen activity. In an in vitro study in human prostate fibroblasts, the isolated pumpkin $\Delta 7$-sterols showed antiandrogenic activity dose-dependently blocking the binding of dihydrotestosterone (DHT). The cultures were incubated with 120 ng labeled DHT for 24 hours and the binding rate was calculated as a difference from the concentration remaining in the supernatant. The binding rate in the control was $63 \%$. In the cultures pre-treated with $120 \mathrm{ng}$ or $240 \mathrm{ng}$ pumpkin sterols (each in a double set-up) the binding rate was $51.7 \%$ and $43.3 \%$ or $37.5 \%$ and $38.3 \%$ respectively (14).

Furthermore, Schmidlin and Kreuter (15) described influence of the Cucurbitae pepo extract on activity of aromatase and 5 - $\alpha$-reductase Type II in the homogenates of human and rat placenta. By using $10 \mathrm{mg} / \mathrm{ml}$-concentration extract, about $50 \%$ reduction of aromatase activity and $90 \%$ of 5 - $\alpha$-reductase Type II inhibition were achieved. Subsequently, in the "in vivo" prostate hypertrophy model the pumpkin extract $(100 \mathrm{mg} / \mathrm{kg})$ reduced prostate weight of $31 \%$ vs $76 \%$ of the subcutaneous Finasteride injection (1 mg/kg). 
Anti inflammatory activity. Three different extracts of pumpkin seeds showed immunological activity suppressing dose dependently mitogen-induced neopterin production and tryptophan degradation induced by cytokine interferon- $\gamma$ (IFN- $\gamma$ ) (16). In particular, pumpkin seeds of Cucurbita pepo (citrullinina GREB. var. styriaca GREB) from biological culture were finely grounded (10 g of the powder was added to $100 \mathrm{ml}$ of medium Roswell Park Memorial Institute (RPMI 1640). Then the peripheral blood mononuclear cells (PMBC) were isolated from the whole blood from healthy human donors and stimulated with phytohaemagglutinin and concanavalin-A. Tryptophan and neopterin concentrations, two biochemical pathways stimulated by cytokine interferon- $\gamma$, were measured in the supernatants in order to assess the anti-inflammatory activity of the pumpkin seeds extracts. Finally, a dose dependant suppression of mitogen-induced neopterin production and tryptophan degradation was recorded compared to control PMBCs. Likewise, Fahim et al. (17) used an experimental murine model of arthritis to test anti-inflammatory activity of pumpkin seed oil administered in intramuscular injection. For comparison, other two groups of rats respectively received indomethacin $-\mathrm{a}$ classic anti-inflammatory agent - and no further treatment. Blood samples were collected to measure: blood glutation (GSH), plasma total proteins, albumin serum sulfhydryl group (SH-gps), ceruloplasmin (CP) and lysosomal marker - N-acetyl- $\beta$-D-glucosaminidase (NAG). After completing the experiment, liver samples were used for determination of glucose-6-phosphate dehydrogenase (G6P DH) activity and protein content of liver homogenates was established. Adjuvant inoculation resulted in decrease of serum SH-gps, with an increase of serum CP reduction of blood glutathione and total proteins and albumins levels. Liver G6P DH activity was markedly increased. The treatment with pumpkin seed oil resulted in normalization of altered parameters, notably in chronic phase, except serum NAG influence. Pumpkin oil administration inhibited paw oedema during the chronic phase in about 44\% as compared to the control untreated group. It reduced also liver G6P DH activity to almost $50 \%$ of the arthritic groups' level. No increase in the antiinflammatory effects of indomethacin combined with pumpkin seed oil was observed.

Bladder contractility. The effects of non-specified water soluble extract of pumpkin seeds and soybean germ extract on in-bladder pressure (cystometrogram) and urination frequency of male rats were tested (18). Pumpkin seed water-soluble extract $(250 \mathrm{mg} / \mathrm{kg})$ compared to control solvent ( $1 \%$ dimethyl sulfoxide diluted in sterile physiological saline) and soybean germ extract significantly increased bladder volume, decreased urination frequency and increased urination delay index. According to the authors, the observed effects of the relaxation of the bladder and decrease of in-bladder pressure are related to the increased productions of $\mathrm{NO}$ via the arginine/NO pathway. Arginine is present in the pumpkin seed extract in two fold the concentrations of other amino acids. It was suggested that arginine/NO metabolism, independently of adrenaline and acetylcholine, is involved in relaxation of urination muscle at a stage of full bladder (19).
Prostate gland growth. Abdel-Rahman et al. (20) performed a comparative study to examine the effect of pumpkin seeds diet implementation on prostate growth. The authors used an experimental model where benign prostatic hyperplasia (BPH) in ventral prostate was induced by orally administering citral $(\mathrm{ClOH} 16 \mathrm{O})$ into stomach of male rats. Citral was administered to all rats except negative control group. The rats were subsequently grouped according to their diet - normal or different level of pumpkin seeds - and sacrificed. Briefly, citral significantly increased prostate weight $(\mathrm{P}<0.05)$, while pumpkin seeds given orally dose-dependently inhibited citral induced hyperplasia of the prostate, especially at high concentration seed dose $(10 \%, \mathrm{p}<0.02)$. In a testosterone-induced BPH murine model Gossell-Williams et al. found that administration of testosterone significantly increased prostate size ratio (weight of prostate/b.w. of the rat) $(\mathrm{p}<$ 0.05 ) although this increase was significantly inhibited by treatment with pumpkin seed oil at $4.0 \mathrm{mg} / 100 \mathrm{~g}$ b.w. Gossell-Williams (21). Likewise, Tsai et al. (22) tested pumpkin seed oil efficacy for 14 days, in experiments performed in rats on the model of prostatic growth induced by subcutaneous daily injection of testosterone (1.25 $\mathrm{mg} / \mathrm{kg} /$ day $)$ together with prazosin $(30 \mu \mathrm{g} / \mathrm{kg} /$ day $)(\mathrm{T}-\mathrm{P})$. Pumpkin seed oil (PSO) $(2.5 \mathrm{ml} / \mathrm{kg} /$ day) extracted from pumpkin seeds was administered concomitantly together with T-P. As compared with T-P alone group, the T-P group treated with $\mathrm{PSO}$ had significant lower weight ratio for ventral prostate $(\mathrm{p}=0.01)$ and lower protein levels within ventral lobe and dorsolateral lobe $(\mathrm{p}=0.03$ and $\mathrm{p}$ $=0.003$, respectively).

Table 1 summarizes all evidence available in the pre-clinical setting.

\section{Clinical setting}

Hamvas et al. (23) reported an overall improvement of urinary symptoms after 10 months of medication with Cucurbita pepo. The daily dosage was $3 \times 2$ capsules in the first month and $3 \times 1$ capsule for the rest of the time. Changes despite pre-treatment conditions in uroflow test and patients symptoms perception were the used outcomes. Control visits were scheduled after 4-7-10 months of medication. At the end of follow up, an improvement in uroflowmetry parameters was recorded (respectively: $\mathrm{Q}_{\max } 15.4$ vs $18 \mathrm{ml} / \mathrm{sec}$, Qave 9.5 us 12.5 $\mathrm{ml} / \mathrm{sec}$, post voiding residual 90 vs $50 \mathrm{ml}$ ). Furthermore, a reduction of nocturia, urinary frequency and relief of urinary pain were reported. Finally, about $90 \%$ of patients felt a "very good" or "good" improvement of their urinary symptoms after therapy. In a multicentre setting, Bach et al. (24) performed a randomized double-blind, placebo-controlled study enrolling 476 men (mean age 63 yrs) suffering from mild or moderate BPH symptoms and at early stages (I or II) of clinical BPH as defined by Alken (25). The study was carried out in accordance with recommendations of the International Consultation on Benign Prostatic Hyperplasia (26). The duration of treatment was 12 months and the main efficacy criterion was the International Prostate Symptom Score (IPSS). After a 1 - month run-in-period under placebo, patients were randomized to daily treatment for 12 months with either $2 \times 500 \mathrm{mg}$ of the soft extract (15-25:1, ethanol 92\%, 
Table 1.

Summary of experimental studies supporting a role of pumpkin seeds in the treatment of BPH-LUTS.

\begin{tabular}{|c|c|c|c|c|}
\hline $\begin{array}{l}\text { BPH-LUTS } \\
\text { etiology role }\end{array}$ & Author, year & Part of plant & Model & Main study finding \\
\hline \multirow{3}{*}{ 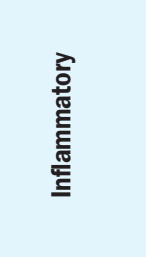 } & Xanthopoulou 2009 & Seed extract & Biochemical for Lipid peroxidation & Inhibited lipid peroxidation \\
\hline & Winkler 2005 & Seed extract & $\begin{array}{l}\text { Biochemical: blood stimulated } \\
\text { mononuclear cells from healthy men }\end{array}$ & $\begin{array}{l}\text { Inflammatory induced pathways (IFN- } \gamma \\
\text { mediated) were reduced }\end{array}$ \\
\hline & Fahim et al. 1995 & Seed oil & Arthritis rats model & $\begin{array}{l}\text { Oxidative parameters commonly altered } \\
\text { during arthritis were modulate; furthermore a } \\
\text { reduction of rats'paw oedema was achieved }\end{array}$ \\
\hline \multirow{2}{*}{ 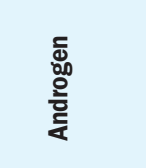 } & Schilcher 1990 & Pumpkin $\Delta 7$-sterols & $\begin{array}{l}\text { Biochemical: human prostate } \\
\text { fibroblasts culture }\end{array}$ & Dihydrotestosterone binding \\
\hline & Schmidlin and Kreuter 2003 & Seed extract & $\begin{array}{l}\text { Biochemical: homogenates } \\
\text { of human and rat placenta }\end{array}$ & $\begin{array}{l}\text { Aromatase and } 5-\alpha \text {-reductase Type II activity } \\
\text { reduction; reduction of prostate weight }\end{array}$ \\
\hline 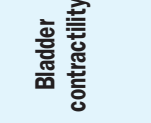 & Hata 2005 & Seed extract & Urodynamic test in rats & $\begin{array}{l}\text { Increase bladder volume } \\
\text { Decrease frequency }\end{array}$ \\
\hline \multirow{3}{*}{ 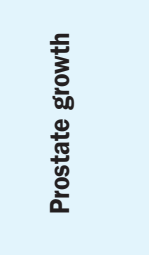 } & Abdel-Rahman 2006 & Seed & $\mathrm{BPH}$ induced with citral in rats & $\begin{array}{l}\text { High concentration seed dose inhibites } \\
\text { prostate growth }\end{array}$ \\
\hline & Gossell-Williams 2006 & Seed oil & $\mathrm{BPH}$ induced with testosterone in rats & $\begin{array}{l}\text { Inhibition of testosterone induced prostatic } \\
\text { hyperplasia }\end{array}$ \\
\hline & Tsai 2006 & Seed & $\begin{array}{l}\text { Testosterone plus Prazosin } \\
\text { induced prostate growth in rats }\end{array}$ & Prostate weight was decreased \\
\hline
\end{tabular}

$\mathrm{m} / \mathrm{m})$ from pumpkin seeds $(\mathrm{n}=233)$ or placebo $(\mathrm{n}=$ 243). Five post-randomization visits were scheduled after 1, 3, 6, 9 and 12 months. An improvement of at least 5 points in the IPSS at study end was defined as a therapy response. Even though the 'placebo effect' was considerable, this therapy response was reported by significantly more patients in the Cucurbita group than in the placebo group $(65 \%$ vs. $54 \%, p=0.021)$. Also, an improvement of at least 3 points in the IPSS was reported by more patients in the Cucurbita group ( $82.5 \%$ ) than in the placebo group (67.9\%, ITT population). The mean reduction in IPSS of 6.7 points (from 17.6 to 10.9) in the pumpkin seed group was significantly greater than the mean reduction of 5.5 points (from 17.7 to 12.2) after placebo treatment $(p=0.014)$. No significant changes were evident in either group in uroflowmetry parameters, residual urine, quality of life, prostate volume or serum prostate specific antigen levels. Likewise, Friederich (27) performed an observational study including 2245 patients with mild or moderate BPH symptoms and administering $500 \mathrm{mg}$ or $1.000 \mathrm{mg}$ of pumpkin seed soft extract daily for 12 weeks. During therapy IPSS scores improved by $41 \%$ (7.7 points, from 18.6 to 10.9 ) and quality of life index scores by $46 \%$ (from 3.4 to 1.8 ). The average frequency of micturition decreased from 6.7 to 5.1 during the day and from 2.3 to 1 during the night. Improvement of dysuric disorders, such as painful urination, micturition burning, feeling of pressure and tension was reported by $52 \%$ of the patients. Diary recorded micturition frequency during the day and during the night was reduced within just 4 weeks to mean values of
5.8 (day) and 2.1 (night), with further improvement after 8 weeks to 5.2 and 1.5 , reaching 4.8 during the day and 1.1 during the night after 12 weeks of treatment. At subgroup analyses, the most pronounced improvement was observed for the micturition frequency during the night, whereas patients with acute disorders benefited most. In these patients nocturia was reduced by $60 \%$ (from 2.35 to 0.94 ), and in patients with chronic complaints by $48 \%$ (from 2.75 to 1.43 ). In a retrospective survey involving urologists in private practice the treatment progression of 185 patients (aged between 44 and 85 years) receiving pumpkin seed soft extract was recorded and evaluated (28). Among those, 173 patients received pumpkin seed soft extract as therapy to treat LUTS due to BPH. Most patients (63\%) took 1 capsule per day, $27 \%$ took 2 capsules, and $9 \%$ of the patients were treated with more than 2 capsules. The recorded observation periods for individual patients ranged between one week and several years. However, for the majority $(81 \%)$ data on the course of treatment were recorded within the first 3 months. Urge symptoms and micturition frequency were reduced in most patients. The proportion of patients having reported more than one micturition during the night at start of treatment was reduced from $90 \%$ to $30 \%$. Residual urine was found to be reduced in $80 \%$ of the patients. Hong et al. (29) carried out a randomized, double-blind, placebo-controlled trial over 12 months, enrolling 47 patients with BPH with mean age of 53.3 years and international prostate symptom score over 8 . The study design contemplated four comparative study arms: sweet potato starch (group 
Table 2.

Clinical studies on pumpkin seeds in men affected of BPH-LUTS.

\begin{tabular}{|c|c|c|c|c|c|}
\hline Author, year & Study design & $\begin{array}{c}\text { Patients } \\
\text { number }\end{array}$ & Comparator & $\begin{array}{l}\text { Treatment } \\
\text { length }\end{array}$ & Outcomes measured \\
\hline Hamvas 1991 & & 60 & Pre-treatment & $10 \mathrm{mo}$ & $\begin{array}{l}\text { - Uroflow features improvement: Qmax } 15.4 \text { vs } 18 \mathrm{ml} / \mathrm{s} \text {; } \\
\text { Qave } 9.5 \text { vs } 12.5 \mathrm{ml} / \mathrm{s} \text {; } \\
\text { - Decrease in nocturia time, relief of dysuria and painful discharge } \\
\text { - About } 90 \% \text { referred a mild or very good improvement } \\
\text { in symptoms gravity }\end{array}$ \\
\hline Bach 2000 & $\begin{array}{l}\text { Randomized } \\
\text { controlled trial }\end{array}$ & 476 & Placebo & $12 \mathrm{mo}$ & $\begin{array}{l}\text { - Significative Increase in response rate (ITT population): } \\
67.5 \% \text { vs } 56.2 \% \\
\text { - Decrease in IPSS } 17.6 \pm 3.7 \text { vs } 10.9 \pm 4.5 \\
\text { - Mean IPSS after treatment/change to baseline (ITT): } 10.9 \pm 4.5 \\
\text { change: }-6.7(-38 \%) \text { vs } 12.2 \pm 5.1 \text { change: }-5.5(-31 \%)\end{array}$ \\
\hline Friederich 2000 & Multicentric & 2245 & Pre-treatment & 12 weeks & $\begin{array}{l}\text { - IPSS decreased from } 18.6 \text { to } 10.9 \text { (by } 1.4 \% \text { ) and QoL score } \\
\text { improved from } 3.4 \text { to } 1.8 \text { (by } 46.1 \% \text { ) } \\
\text { - } 96 \% \text { reported no undesired side effects }\end{array}$ \\
\hline Burbach 2002 & Retrospective & 185 & Pre-treatment & $3 \mathrm{mo}$ & - Decrease in storage symptoms, nocturia (and PVR) \\
\hline Hong 2009 & $\begin{array}{l}\text { Randomized placebo- } \\
\text { controlled trial }\end{array}$ & 47 & Placebo (four arms) & $12 \mathrm{mo}$ & $\begin{array}{l}\text { Overall: } \\
\text { - Decrease IPSS: } 20.7 \pm 2.3 \text { vs } 8.7 \pm 1.5 \\
\text { - Improvement of QoL score: } 3.4 \pm 0.4 \text { vs } 2.5 \pm 04\end{array}$ \\
\hline Vahlensieck 2015 & $\begin{array}{l}\text { Randomized } \\
\text { controlled trial }\end{array}$ & 1431 & $\begin{array}{l}\text { Placebo } \\
\text { (three arms: } \\
\text { pumpkin seed, } \\
\text { pumpkin seed } \\
\text { extract and placebo) }\end{array}$ & $12 \mathrm{mo}$ & $\begin{array}{l}\text { - Decrease in IPSS (ITT): }-5.4 \pm 5.1,-4.2 \pm 5.4 \text { vs }-4.0 \pm 5.6 \\
\text { - IPSS response rate increased by } 6 \% \\
\text { - Improve in QoL } 36 \% \text { and } 33,4 \% \text { vs } 29,2 \%\end{array}$ \\
\hline
\end{tabular}

A, placebo, $320 \mathrm{mg} /$ day), pumpkin seed oil (group B, $320 \mathrm{mg} /$ day), saw palmetto oil (group C, $320 \mathrm{mg} /$ day) or pumpkin seed oil plus saw palmetto oil (group D, each $320 \mathrm{mg} /$ day). International prostate symptom score, quality of life, serum prostate specific antigen, prostate volume and maximal urinary flow rate were measured. So far, in groups B, C and D, the international prostate symptom score were reduced after 3 months (respectively from $20.7 \pm 2.3,18.3 \pm 2.0,19.0 \pm 2.6$ to $8.7 \pm 1.5$, $9.1 \pm 1.4,4.7 \pm 17)$. Quality of life score was improved after 6 months in group D (pumpkin seed oil plus saw palmetto oil) from $3.8 \pm 0.4$ to $2.5 \pm 0.4$ and was maintained stable afterwards while those of groups B (pumpkin seed oil) and $C$ were improved after 3 months, compared to the baseline value respectively from $4.2 \pm 0.4$ to $3.0 \pm 0.4$ and from $3.6 \pm 0.3$ to $3.0 \pm 0.4$ ). Finally, no difference was found in prostate volume in all treatment groups. Maximal urinary flow rate were gradually improved in groups B (pumpkin seed oil) and C, with statistical significance after 6 months in group B and after 12 months in group C. More recently, Vahlensieck et al. (30) investigated the efficacy of pumpkin seed in men with LUTS suggestive of BPH performing a placebo controlled three-armed randomized trial. Overall 1431 patients (aged 50-80 years) were randomly assigned to either pumpkin seed ( $5 \mathrm{~g}$ b.i.d.), capsules with pumpkin seed extract (500 mg b.i.d.) or placebo. The primary outcome was a decrease in IPSS of $>5$ points from baseline after 12 months. Secondary outcome measure included IPSS - related quality of life, IPSS single items and diary recorded nocturia. After 12 months, the response rate differed significantly between pumpkin seed and placebo (58\% vs 47\%). Overall, 12 months of treatment with pumpkin seed led to a clinically relevant reduction in IPSS from $(15.9 \pm 1.8$ and $15.8 \pm 1.9$, to $11.4 \pm 5.5$ and $10.2 \pm 5.1$ ) compared with placebo (from $16.1 \pm 1.9$ to $11.7 \pm 5.4$ ).

\section{Adverse effects}

To note, no adverse effects were registered from above open clinical studies of pumpkin seeds. Only mild gastrointestinal complaints (diarrhoea, nausea, vomiting) in

Figure 2.

International Prostatic Symptoms Score analyzed in clinical studies.

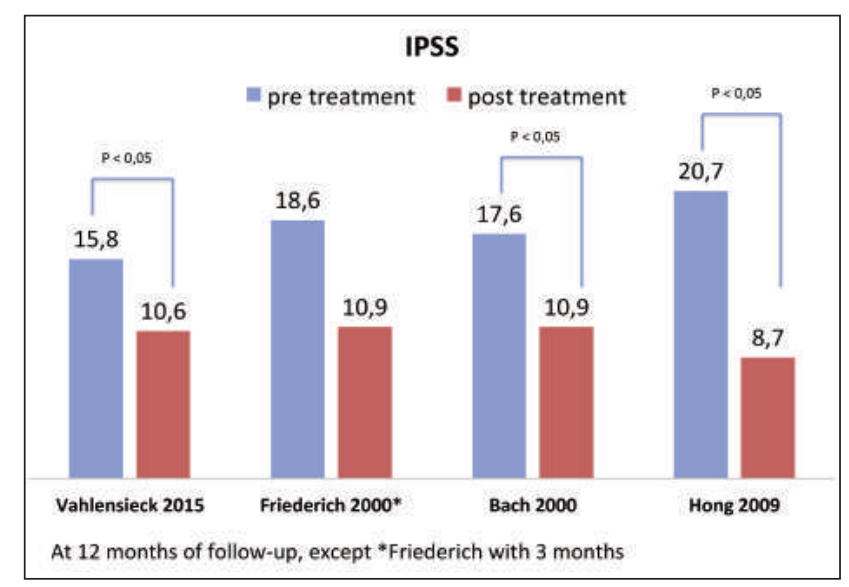


Figure 3.

Quality of Life assessment.

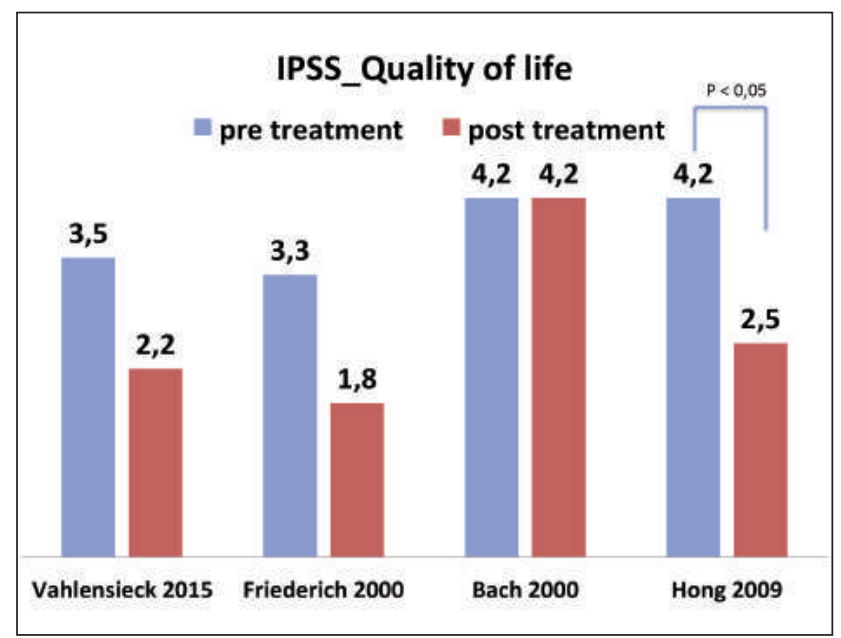

Figure 4.

$Q_{\text {max }}$ assessment in clinical studies.

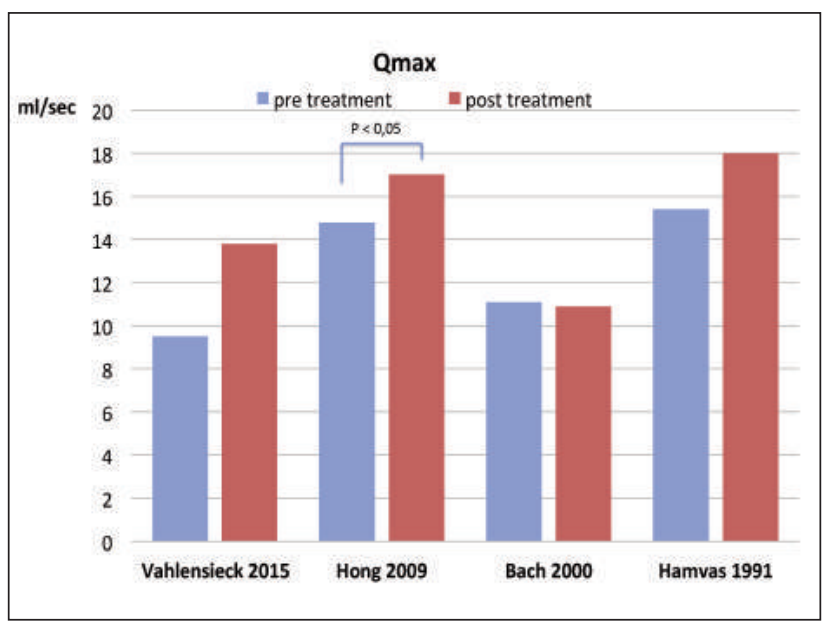

no more than $4 \%$ of the patients was reported in in Friederich study whereby it seems that upon administration within the therapeutic dose range, there is no risk of serious side effects on all three RCTs. No sexual side effects were reported during the use of Cucurbita pepo compounds.

Table 2 shows all clinical studies performed in the management of LUTS-BPH. Moreover, Figure 2, Figure 3 and Figure 4 show impact of the Cucurbita pepo on IPSS, uroflowemetry parameters and patients QoL, respectively.

\section{Discussion}

\section{Main findings}

Several studies performed in the pre-clinical and clinical setting showed that the use of Cucurbita pepo in the management of patients affected by LUTS-BPH seems to be useful for improving symptoms and quality of life. Several aspects should be taken into account; in particu- lar, some limitations of the evidence available need to be considered.

\section{Analysis of the evidences in the context of the current knowledge}

More recent knowledge about the physiological regulation of bladder function makes it plausible that ubiquitous substances may also contribute to the overall effect of pumpkin seeds, in particular for maintaining normal bladder function and preventing functional disorders. Fatty oil of pumpkin seeds is characterized by a high content of linoleic acid, accounting for 35-68\% of the total fatty acids $(31,32)$ Administration of this essential precursor of prostaglandin metabolism (formation of PGE2 and PG2 $\alpha$ ) might cause an increase in prostaglandin synthesis. Prostaglandins are formed by the detrusor muscle and increase its tone (33) resulting in an improved bladder function.

The average tocopherol content of soft-shelled pumpkin seeds is $0.5 \mathrm{mg} / \mathrm{g}$, whereas - in contrast to most other plant oils $-\gamma$-tocopherol is present in five- to ten-fold higher concentrations than the $\alpha$-isomer $(34,35)$.

According to more recent studies, $\gamma$-tocopherol is thought to be significantly involved in the preventive role of vitamin $\mathrm{E}$ and also to have a beneficial effect in chronic inflammation (36-40). Medicinal pumpkin seeds are rich in amino acids such as the NO precursors arginine, glutamine and aspartic acid as well as $\gamma$-aminobutyric acids. These are involved in the regulation of bladder function as direct or indirect central neurotransmitters (41-43).

Observational studies (27), retrospective surveys (28) and randomized controlled trials $(24,29,30)$ provide further evidence on beneficial effects of Cucurbita pepo for patients with LUTS related to benign prostatic hyperplasia, as reduction of urge and micturition frequency was observed. The published literature shows that the benefits of pumpkin seeds treatment depend on the tonic influence on the bladder, sphincter relaxation and alleviation of micturition symptoms. It was therefore suggested that pumpkin seeds could be used in patients without significant obstruction of the prostate and low risk for disease progression (44). Provided that the patient undergoes regular urological control visits, medical treatment with seeds of Cucurbita pepo can be recommended for patients with micturition symptoms related to BPH in early disease stages, including those with symptoms of overactive bladder.

\section{Limits}

The few available studies were often outdated and enrolled a small number of patients, and only three RCTs were of good quality. Other limits are difficulties in data extraction on changes in patients classification (Alken versus IPSS). Nevertheless all studies analyzed showed improvement in micturition parameters related to LUTS/BPH.

\section{Conclusion}

In the context of the present narrative review, Cucurbita pepo seems to show significant efficacy in improving urinary symptoms with mild adverse effects however few clinical studies support the use of that drug. Moreover, 
all clinical studies are based on the evidence raising from experimental studies in pre-clinical setting that showed an interesting action of pumpkin seed elements on some $\mathrm{BPH}$ etiological mechanism. Large randomized study are needed to confirm these interesting result and recommend the use of pumpkin seed in the management of patients affected by LUTS due to BPH.

\section{REFERENCES}

1. McVary KT, Roehrborn CG, Avins AL, et al. Update on AUA Guideline on the Management of Benign Prostatic Hyperplasia. J Urol. 2011; 185:1793-1803.

2. Roehrborn CG. Chapter 91 - Benign prostatic hyperplasia: etiology, pathophysiology, epidemiology, and natural history. In: Kavoussi LR, Novick AC, Partin AW, Peters CA editor(s). Campbell-Walsh Urology. 10th Edition. Vol. 3, Philadelphia: Elsevier Saunders, $2011 b$.

3. Vignozzi L, Gacci M, Maggi M. Lower urinary tract symptoms, benign prostatic hyperplasia and metabolic syndrome. Nat Rev Urol. 2016; 13:108-19.

4. Management of Non-Neurogenic Male Lower Urinary Tract Symptoms (LUTS), incl. Benign Prostatic Obstruction (BPO) in European Association of Urology Guidelines, available on https://uroweb.org/guidelines/

5. Cai T, Morgia G, Carrieri G, et al. An improvement in sexual function is related to better quality of life, regardless of urinary function improvement: results from the IDIProst ${ }^{\circledR}$ Gold Study. Arch Ital Urol Androl. 2013; 85:184-9.

6. Martindale. The Complete Drug Reference. The Pharmaceutical Press 2010

7. ESCOP. Cucurbitae semen (Pumpkin Seed). In: ESCOP Monographs. 2nd edition, supplement 2009. European Scientific Cooperative on Phytotherapy, editor. Georg Thieme Verlag, Stuttgart 2009; 50-56.

8. Müller C, Bracher F. Determination by GC-IT/MS of phytosterols in herbal medicinal products for the treatment of lower urinary tract symptoms and food products marketed in Europe. Planta Med. 2015; 81:613-20.

9. Garg VK, Nes WR. Occurrence of $\Delta 5$-sterols in plants producing predominantly $\Delta 7$-sterols: studies on the sterol compositions of six cucurbitaceae seeds. Phytochemistry. 1986; 25:2591-2597.

10. Schilcher H, Dunzendorfer U, Ascali F. Delta-7-sterole, das prostatrope Wirkprinzip in Kurbissamen? Urologe B. 1987; 27:316319.

11. Strobl M. $\Delta 7$-Sterole und $\Delta 7$-Sterolglycoside aus Samen von Cucurbita pepo L: Isolierung und Strukturaufklärung. Doctoral Thesis, Ludwig-Maximilians-Universität München, 2004.

12. Procida G, Stancher B, Catenia F, Zacchignaa M. Chemical composition and functional characterisation of commercial pumpkin seed oil. J Sci Food Agric 2013; 93: 1035-1041.

13. Xanthopoulou MN, Nomikos T, Fragopoulou E, Antonopoulou S. Antioxidant and lipoxygenase in hibitory activities of pumpkin seed extracts. Food Res Int. 2009; 42:641-646.

14. Schilcher H, Schneider HJ. Beurteilung von Kürbissamen in fixer Kombination mit weiteren pflanzlichen Wirkstoffen zur Behandlung des Symptomenkomplexes bei BPH. Urologe [B] 1990; 30:62-6.

15. Schmidlin CB, Kreuter MH. Cucurbita pepo. Möglicher Einfluss auf hormonelle Ungleichgewichte bei Inkontinenz. Z. Phytotherapie. 2003; 3:16-18.
16. Winkler C, Wirleitner B, Schroecknadel K, et al. Extracts of pumpkin (Cucurbita pepo L.) Seeds suppress stimulated peripheral blood mononuclear cells in vitro. Am J Immunol. 2005; 1:6-11.

17. Fahim AT, Abd-el-Fattah AA, Agha AM, Gad MZ. Effect of pumpkin-seed oil on the level of free radical scavengers induced during adjuvant-arthritis in rats. Pharmacol Res. 1995; 31:73-79.

18. Hata, Tanahashi S, Wakida Y, et al. Effects of pumpkin seed extract on urinary bladder fun ction in anesthetized rats. Med Sci Pharm Sci. 2005; 54:1-10.

19. Andersson KE, Wein AJ. Pharmacology of the Lower Urinary Tract: Basis for Current and Future Treatments of Urinary Incontinence. Pharmacol Rev. 2004; 56:581-63.

20. Abdel-Rahman MK. Effect of pumpkin seed (Cucurbita pepo L) diets on benign prostatic hyperplasia (BPH): chemical and morphometyric evaluation in rats. World J Chem. 2006; 1:33-40.

21. Gossell-Williams M, Lyttle K, Clarke T, Gardner M, Simon O. Supplementation with pumpkin seed oil improves plasma lipid profile and cardiovascular outcomes of female non-ovariectomized and ovariectomized Sprague-Dawley rats. Phytother-Res 2008; 22:873-877

22. Tsai Y-S, Tong Y-C, Cheng J-T, Lee C-Ho. Pumpkin seed oil and phytosterol-F can block testosterone/prazosin-induced prostate growth in rats. Urol Int. 2006; 77:269-274.

23. Hamvas A, Corradi GY, Hegedüs, Frang D. Experience with the Peponen ${ }^{\circledR}$ capsule in the management of benign prostatic hyperplasia. Int Urol Nephrol. 1991; 23:51-55.

24. Bach D. Placebokontrollierte Langzeittherapiestudie mit Kürbissamenextrakt bei BPH-bedingten Miktionsbeschwerden. Urologe [B] 2000; 40:437-443, 2000 Erratum, in: Urologe [B] 2001; 41:42.

25. Alken CE. Konservative Behandlung des Prostata-Adenoms und Stadien-Einteilung. Urologe [B] 1973; 13:95-8.

26. Aso Y, et al. Clinical Research Criteria. In: Cockett, A.T.K., S. Khoury, Y. Aso, C. Chatelain, L. Denis, K. Griffiths, G. Murphy. The 2nd International Consultation on Benign Prostatic Hyperplasia, Paris- June 27-30,1993; 345-358.

27. Friederich M, Theurer C, Schiebel-Schlosser G. Prosta Fink Forte $^{\circledR}$ kapseln in der Behandlung der benignen Prostatahyperplasie. Eine multizentrische Anwendungsbeobachtung an 2245 Patienten. Forsch Komplementärmed Klass Naturheikd. 2000; 7:200-204.

28. Burbach, S. Behandlung von Miktionsbeschwerden bei BPH, Fallberichte aus der Praxis. Extracta urologica 2002; 12:18-21.

29. Hong H, Kim CS, Maeng S. Effects of pumpkin seed oil and saw palmetto oil in Korean men with symptomatic benign prostatic hyperplasia. Nutr Res Pract. 2009; 3:323-7.

30. Vahlensieck W, Theurer C, Pfitzer E, et al. Effects of pumpkin seed in men with lower urinary tract symptoms due to benign prostatic hyperplasia in the one-year, randomized, placebo-controlled GRANU study. Urol Int. 2015; 94:286-95.

31. Hänsel R, Keller K, Rimpler H, Schneider G (Hrsg). Cucurbita in: Hagers Handbuch der pharmazeutischen Praxis, 5. Ed., Bd 4, Heidelberg: Springer-Verlag 1992; pp 1068-79.

32. Schilcher H. Cucurbita-Species - Kürbis-Arten. Zeitschrift für Phytotherapie. 1986; 7:19-23.

33. Abrams PH und Fenneley L. The actions of prostaglandins on the smooth muscle of the human urinary tract. Br J Urol. 1976; 47:909-915.

34. Murkovic M, Hillebrand A, Winkler J, Pfannhäuser W. 
Variavility of Vitamin E content in pumpkin seeds (Cucurbita pepo L.) Z. Lebensm. Unters. Forsch, 1996a; 202:275-278.

35. Rucker RB, Suttie JW, McCormick DB, Machlin LJ. Handbook of Vitamins 3rd ed. New York: Marcel Dekker Inc. 2001; pp 183-4.

36. Freeman VL, Meydani M, Yong S, et al. Prostatic levels of tocopherols, carotenoids, and retinol in relation to plasma levels and selfreported usual dietary intake. Am J Epidemiol. 2000; 151:109-18.

37. Giovanucci E. Gamma-tocopherol: a new player in prostate cancer prevention? J Natl Cancer Inst. 2000; 92:1966-7.

38. Helzlsouer KJ, Huang HY, Alberg AJ, et al. Association between alpha-tocopherol, gamma-tocopherol, selenium, and subsequent prostate cancer. J Natl Cancer Inst. 2000; 92:2018-23.

39. Hensley K, Benaksas EJ, Bolli R, et al. New perspectives on vitamin E: gamma-tocopherol and carboxyelthylhydroxychroman metabolites in biology and medicine. Free Radic Biol Med. 2004; 36:1-15.

40. Jiang Q, Ames BN. Gamma-Tocopherol, but not alpha-tocopherol, decreases proinflammatory eicoanoids and inflammation damage in rats. FASEB J. 2003; 17:816-22.

41. De Groat. Anatomy of the central neural pathways controlling the lower urinary tract. Eur Urol. 1998; 34 (Suppl 1): 2-5.

42. Korting GE, Smith SD, Wheeler MA, et al. A randomized double-blind trial of oral L-arginine for treatment of interstitial cystitis.J Urol. 1999; 161:558-65.

43. Persson K, Igawa Y, Mattiasson A, Anderson KE. Inhibition of the arginine/nitric oxide pathwy causes bladder hyperactitivy in the rat. Acta Physiol Scand. 1991; 144:107-8.

44. Madersbacher S, Ponholzer A, Berger I, Marszałek M. Medical Management of BPH: Role of Plant Extracts. EAU EBU Update Series. 2007; 5:197-205.

\section{Correspondence}

Rocco Damiano, MD

damiano@unicz.it

Department of Urology, Magna Graecia University of Catanzaro

Viale Europa - Germaneto 88100 Catanzaro, Italy

Tommaso Cai, MD

Department of Urology, Santa Chiara Regional Hospital

Trento, Italy

Paolo Fornara, MD

Department of Urology, Martin-Luther-University

Halle Saale, Germany

Corrado Antonio Franzese, MD

Urology, ASL NA3 SUD, Naples, Italy

Rosario Leonardi, MD

Urology, GECAS Institute, Catania, Italy

Vincenzo Mirone, MD

Department of Urology, University of Naples, Federico II

Naples, Italy 